\title{
MEASUREMENTS OF THE EFFECT OF SPECIMEN SIZE ON YOUNG'S MODULUS AND TENSILE STRENGTH OF POLYSILICON
}

\author{
William N. Sharpe, Jr. and Kevin Turner \\ Department of Mechanical Engineering, \\ The Johns Hopkins University \\ Baltimore, Maryland 21218-2686
}

\author{
Richard. L. Edwards \\ Applied Physics Laboratory \\ The Johns Hopkins University \\ Laurel, MD 20723-6099
}

\begin{abstract}
Techniques and procedures are described for tensile testing of polysilicon specimens that are 1.5 or $3.5 \mu \mathrm{m}$ thick and have various widths and lengths. The specimens are fixed to the wafer at one end and have a large free end that can be gripped by electrostatic forces. This enables easy handling and testing and permits the deposition of 18 specimens on a one-centimeter square portion of a wafer. The displacement of the free end is monitored, which allows one to extract Young's modulus from the force-displacement record. Some of the wider specimens have two gold lines applied so that strain can be measured interferometrically directly on the specimen to record a stressstrain curve.

The specimens were produced at the Microelectronics Center of North Carolina (MCNC). Earlier measurements on wider MCNC specimens that were $3.5 \mu \mathrm{m}$ thick gave a modulus of $169 \mathrm{GPa}$. The narrower $3.5 \mu \mathrm{m}$ thick specimens tested here had a modulus of $142 \mathrm{GPa}$, and the $1.5 \mu \mathrm{m}$ thick specimens showed $136 \mathrm{GPa}$. The strengths measured earlier on wider specimens averaged $1.20 \mathrm{GPa}$, but the average strength for each thickness tested here was $1.3 \mathrm{Gpa}$. The different widths and lengths for each thickness had no systematic effect on the Young's modulus or strength.
\end{abstract}

\section{INTRODUCTION}

There is an obvious need for accurate measurements of the elastic and strength properties of polysilicon, but conducting stress-strain tests is not so easy. In earlier work [1], 3.5 $\mu \mathrm{m}$ thick polysilicon tensile specimens that were $600 \mu \mathrm{m}$ wide and $4 \mathrm{~mm}$ long were prepared by etching away the underlying silicon wafer. The large grip ends were glued into a small test machine and two supporting side strips were then cut with a diamond saw to completely free the specimen. Friction in the load train was eliminated by a linear air bearing, and the specimen was elongated by an electrostatic actuator.

Strain was measured by laser interferometry between two gold lines $0.5 \mu \mathrm{m}$ thick and $20 \mu \mathrm{m}$ wide that were deposited on the central portion of the tensile specimen. In fact, two sets of gold lines were used to enable the first-ever measurements of Poisson's ratio of this thin material. Very consistent results were obtained - Young's modulus of $169 \pm 6 \mathrm{GPa}$ and strength of $1.20 \pm 0.15 \mathrm{GPa}$ for 48 tests from five different production runs. Nineteen of those tests had two sets of gold lines to measure Poisson's ratio of $0.22 \pm 0.01$.

The disadvantage of this approach is that only one specimen is available per die and the etching procedure is time consuming. Tuschiya et al [2] conceived a new technique in which narrow tensile specimens are deposited with one end fixed and the other free so that it can be gripped by electrostatic forces. This makes it easier to handle the specimens and allows one to deposit many specimens on a die. Tuschiya has conducted an extensive series of tests to measure the strength of polysilicon.

Greek et al [3] tested polysilicon tensile specimens that have one end fixed to the substrate. The free end has a large ring into which a probe is fitted for a mechanical connection to the specimen. They measured the overall displacement as a function of force and used specimens of two different lengths to eliminate the unknown stiffness of the test system. By this method, they measured both Young's modulus and strength.

The approach used here is a combination of the three described above. The specimens are similar in shape to those of Tuschiya et al so that they can be gripped electrostatically, and displacement is recorded as well. Some of the wider specimens have two gold lines on them (none are wide enough for two sets) so that strain can be measured directly.

\section{SPECIMEN SHAPE AND TEST SETUP}

Figure 1 is a schematic of the new test setup and of the specimen. The polysilicon specimen remains fastened to the substrate at one end; the other large end is gripped electrostatically by an insulated probe. The specimen substrate is mounted on a piezoelectric stage with a least count displacement on the order of 10 nanometers. The probe is attached to a load cell mounted on a 3-axis micrometer stage to allow positioning and alignment. The laser is focused on two thin gold lines deposited in the center of the tensile specimen; this generates interference fringes which are monitored with photodiode arrays to record their motion [1]. A capacitancebased displacement transducer records the displacement of the specimen mount. The test is conducted under computer control and records force, strain, and displacement.
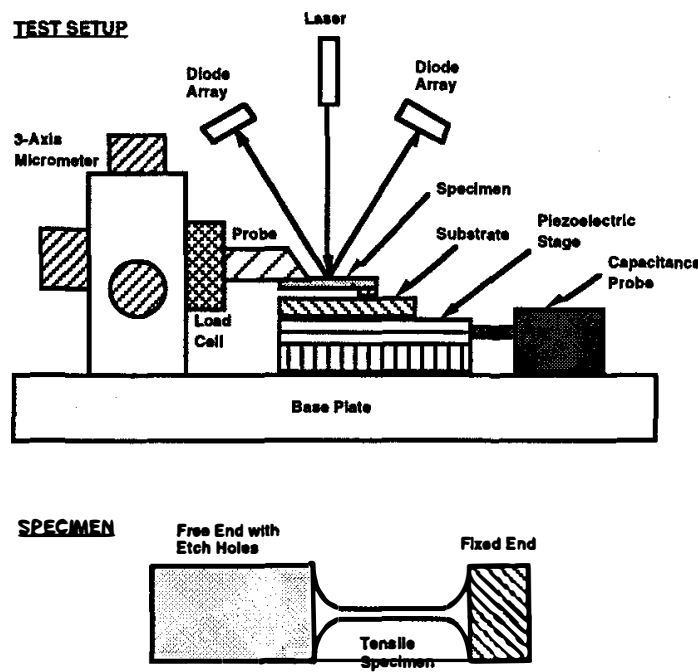

Figure 1. Schematic of the specimen and the test setup. 
Figure 2 is a photograph of the specimens that were manufactured by the Microelectronics Center of North Carolina on their MUMPs 19 run. 'There are 18 specimens on a onecentimeter square chip; nine are $1.5 \mu \mathrm{m}$ thick and nine are 3.5 $\mu \mathrm{m}$ thick. The specimens have various widths ranging from 2 to $50 \mu \mathrm{m}$ and lengths ranging from 20 to $500 \mu \mathrm{m}$ to permit examination of the effect of specimen size on the mechanical properties.

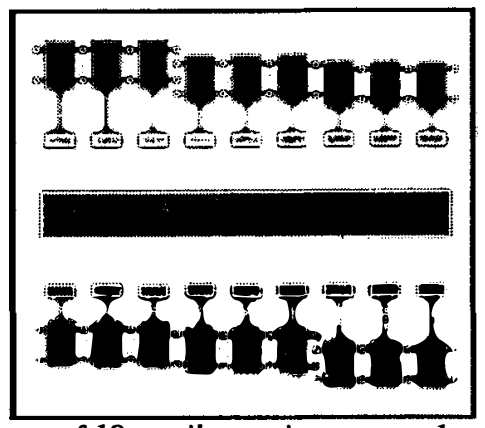

Figure 2. Photo of 18 tensile specimens on a 1-cm square die.

\section{FORCE-DISPLACEMENT AND STRESS-STRAIN}

One can extract Young's modulus from the record of the force versus displacement of the system if the stiffness of the measurement system is known. Figure 3 is a plot of the forcedisplacement record for two specimens on the same die, and the modulus is calculated using a system stiffness of $0.00651 \mathrm{~N} / \mu \mathrm{m}$.

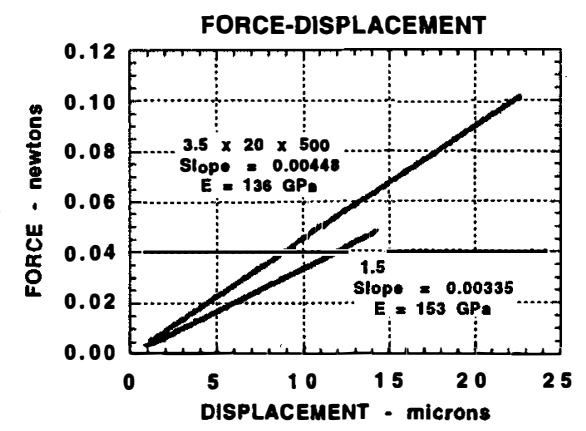

Figure 3. Force-displacement record of two specimens identical in shape, but of different thicknesses.

One can also measure the strain directly on the larger specimens as reported earlier [1], and two stress-strain curves are shown in Figure 4.

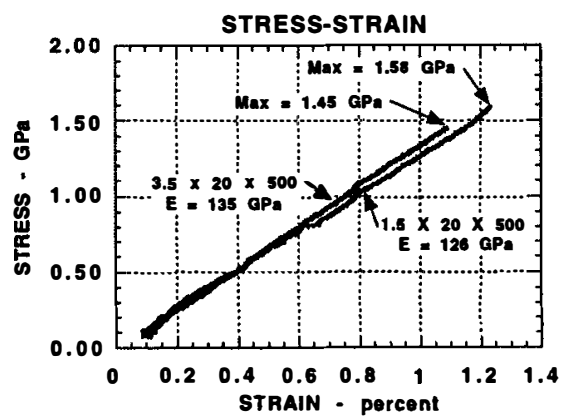

Figure 4. Stress-strain record of the same two specimens whose force-displacement curves are shown in Figure 3.

Figures 3 and 4 show similar behavior (within the scatter of the results) for the two specimens of different thickness.

\section{PRELIMINARY MODULUS AND STRENGTH DATA}

Several tests have been conducted, and an extensive test program is underway. Figures 5 and 6 show the preliminary results to date.

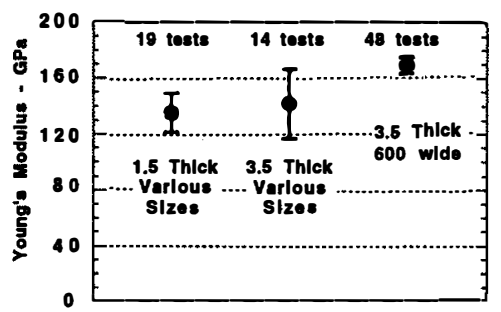

Figure 5. Modulus data for various sizes.

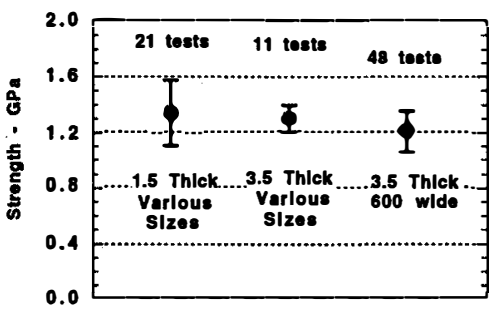

Figure 6. Strength data for various sizes.

No trends of modulus or strength with specimen width or length were observed for either thickness.

\section{CONCLUSIONS}

The decrease in modulus as the specimen size gets smaller is in contradiction with what one would expect. On the other hand, the variation in strength, although slight, is not so surprising. The microstructure of vapor deposited polysilicon is columnar in structure perpendicular to the film [1]. It is not unreasonable to expect that the nature of this grain structure changes as the 'mold' into which the polysilicon is deposited becomes smaller. Detailed microstructural examinations are underway to complement the continuing test program.

\section{ACKNOWLEDGMENTS}

This research was sponsored by the National Science Foundation and by the Air Force Office of Scientific Research.

\section{REFERENCES}

1. W. N. Sharpe, Jr., , B. Yuan, R. L. Edwards, and R.Vaidyanathan, "Measurements of Young's modulus, Poisson's ratio, and Tensile Strength of Polysilicon', Proc. Tenth IEEE International Workshop on Microelectromechanical Systems, Nagoya, Japan, pp. 424-429 (1997).

2. T. Tsuchiya, O. Tabata, J. Sakata, and Y. Taga, "Specimen Size Effect on Tensile Strength of Surface Micromachined Polycrystalline Silicon Thin Films', Proc. Tenth IEEE International Workshop on Microelectromechanical Systems, Nagoya, Japan, pp. $529-534$ (1997).

3. S. Greek and S. Johansson, "Tensile Testing of Thin Film Microstructures", Micromachined Devices and Components III SPIE, Volume 3224, pp. 344-351 (1997). 